\title{
Grounding Systems for Power Supply Facilities
}

\author{
Vladimir Anatolevich Konusarov*, Evgeniy Alekseevich Shutov, Tatyana Evgenievna Turukina \\ Division for Power and Electrical Engineering, School of Energy and Power Engineering, National Research Tomsk Polytechnic \\ University, Tomsk, Russia \\ Email: ^Konusarov@mail.ru
}

How to cite this paper: Konusarov, V.A., Shutov, E.A. and Turukina, T.E. (2019) Grounding Systems for Power Supply Facilities. Energy and Power Engineering, 11, 1-14.

https://doi.org/10.4236/epe.2019.111001

Received: September 30, 2018

Accepted: January 20, 2019

Published: January 23, 2019

Copyright $\odot 2019$ by author(s) and Scientific Research Publishing Inc. This work is licensed under the Creative Commons Attribution International License (CC BY 4.0).

http://creativecommons.org/licenses/by/4.0/ (c) (i) Open Access

\begin{abstract}
The goal of this work is creation of optimal grounding model at the substation $10 / 0.4 \mathrm{kV}$ of the urban power distribution network. The electric current can pose a major threat to the man's life and health. In addition to pose a threat for health, the rise of the short circuit, as a consequence of insulation faults, poses a threat to retirement of electric systems and fire risks. The reliable grounding system design has significant implications for protection of human being as well as for electrical facility protection. The set objective was performed on the base of analytical and software-based methods. Analytical method gives a qualitative indication at each step in analysis. It also allows evaluating the values effect on the result, but the method is not susceptible of tolerable accuracy, that is why analytical method serves as initial approximation in differentiating. Specified estimation can be performed in such software package as MATLAB or ETAP. Software-based estimation is based on the finite element method (FEM), the main advantage of which is the ability to create different forms of grounding and allows obtaining distribution graphs of the step potential on the earth's surface and touch potential. The calculation results in comparison of analytical and software-based methods taking into account the grounding optimization. There are conclusions on the most effective ground network.
\end{abstract}

\section{Keywords}

Grounding Device, Current-Using Equipment, Short-Circuit Fault, Single Phase-to-Ground Fault, Main Step Down Substation (MSDS), TN-C, TN-S, TN-C-S, TT, IT, Indirect Contact, Step Potential, FEM, IEEE

\section{Introduction}

The ground is the most important processing protection method against electric-shock hazard. A considerable protection of human and power supply objects 
against different types of overvoltage requires new effective ground network of electric installation. Today a lot of works consider the problems of protection of people and equipment in the event of damage in urban electrical networks and electrical installations. This paper is devoted to the design and estimation of grounding at the substation of the urban power distribution network [1].

Technical details of electric installations and mains are needed to use different types of ground networks [2]. The type of ground network is the parameter that characterize the ratio between ground and neutral of open conductive non-current-carrying parts of electric energy receiver and the ration between ground and neutral of electric units with voltage up to 1000 V. Russian Rules of Electrical Facilities Maintenance provides an application of three mode of neutral and conductive part operation, Table 1 [3].

In turn, grounding mode of $T N$ neutral can be three types, Table 2.

Each of the above ground methods is not universal. That's why in the network designing it is necessary to be guided by advantages and disadvantages, technical and economic assessment and selecting the grounding mode.

In the general case, all network patterns of protection ground can be divided into three group:

1) Local (individual) - grounding devices are not connected to a common ground network. It is performed by earthing, located near objects to be grounded.

2) Transmission network-branches are connected to the grounding device or in such cases when there are several grounding devices that to the one of these.

Table 1. The mode of neutral operation.

\begin{tabular}{cl}
\hline $\begin{array}{c}\text { Type of ground } \\
\text { network }\end{array}$ & \multicolumn{1}{c}{ Description } \\
\hline$T N$ & $\begin{array}{l}\text { A system in which the supply equipment neutral is solidly grounded, electric } \\
\text { installation cases are connected to the neutral wire. }\end{array}$ \\
& $\begin{array}{l}\text { A system in which the neutral of supply equipment and electric installation } \\
\text { case are solidly grounded, open conductive non-current-carrying parts of } \\
\text { electrical installation are grounded with the help of grounding device, which is } \\
\text { electrically independent from the supple neutral. }\end{array}$ \\
& $\begin{array}{l}\text { A system in which the supply equipment neutral is insulated and grounded } \\
\text { through apparatus and high-resistance equipment, electric installation cases } \\
\text { are solidly grounded. }\end{array}$ \\
\hline
\end{tabular}

Table 2. Types of the grounding mode of TNneutrals.

\begin{tabular}{cl}
\hline Type of ground network & \multicolumn{1}{c}{ Description } \\
\hline$T N-C$ & $\begin{array}{l}T N \text { system in which protective and neutral conductors are grouped into } \\
\text { one conductor along the whole length of system. }\end{array}$ \\
$T N-S$ & $\begin{array}{l}T N \text { system in which protective and neutral conductors are isolated from } \\
\text { each other. }\end{array}$ \\
$T N-C-S$ & $\begin{array}{l}\text { TN system in which protective and neutral conductors are grouped into } \\
\text { one conductor at the advance section, but further protective and neutral } \\
\text { conductors are isolated from each other. }\end{array}$
\end{tabular}


Transmission grounding conductor in this case is raised below phase conductors through overhead line supports and fastened to poles using the hook without insulators.

3) Ringed network-ground networks are connected to the grounding device and grounding electrode. It is done in the same way as the transmission network using the cable which is raised below phases and fastened to overhead line supports. Ringed ground network includes the grounding device and two branch transmission lines which are joined together on the corporate premises [4].

The safety grounding device schema is illustrated in Figure 1.

In the next section is described the main idea of the grounding device estimation, the exact evaluation of a grounding device and its optimization are shown in paragraph "Software-based evaluation of a grounding device". Actual data and conclusion are shown in the paragraph "Calculation data".

\section{Analytical Calculation of a Grounding Device}

This paper focuses on the existing and running in operation substation of Tomsk city distribution grid. Electrical installation works with the insulated neutral on the high-voltage side and with $T N-S$ mode of neutral operation on the side of $0.4 \mathrm{kV}$, Figure 2. Networks with the insulated neutral are characterized by low currents during single phase-to-ground fault, not more $20 \mathrm{~A}$ at the voltage $10 \mathrm{kV}$. On the side of $0.4 \mathrm{kV}$ with the solidly grounded neutral the short circuit current value mainly depends on winding circuit of a feeder transformer; at the winding circuit $\Delta / Y$ the current value of single and three phase faults are practically equal. The short circuit current values impact which way will be done

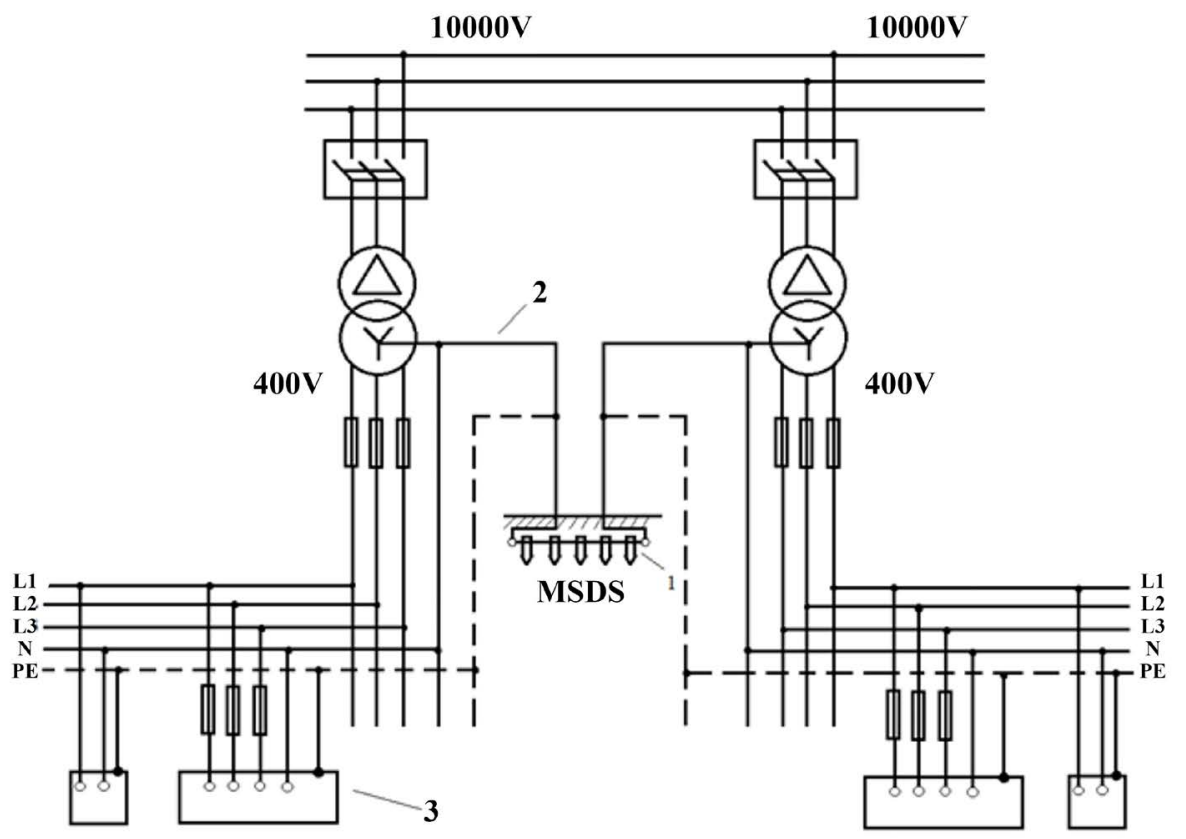

Figure 1. Safety ground schema: 1-the main ground source, 2-MSDS's grounding bus, 3 -an electric installation. 


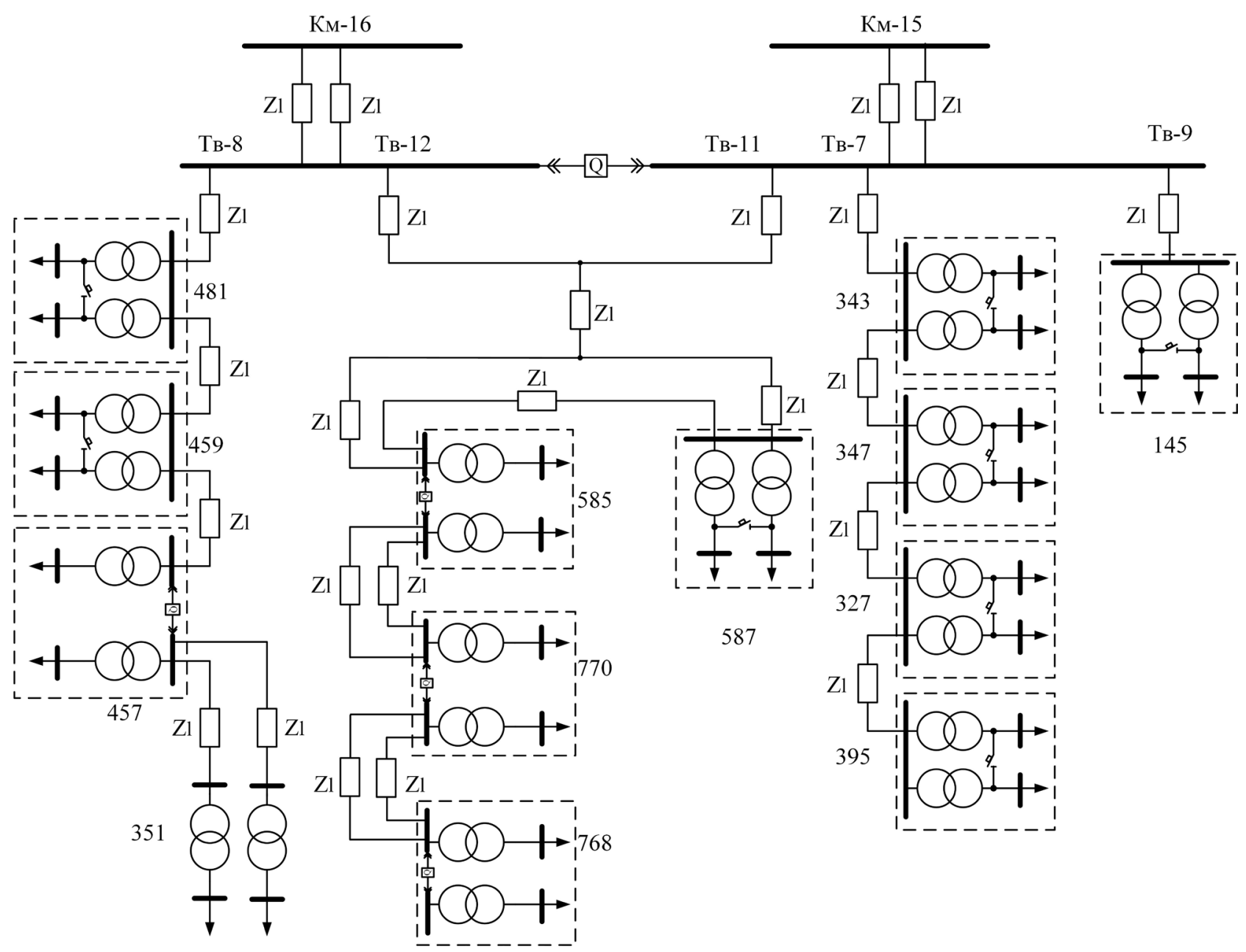

Figure 2. The fragment of urban power distribution network.

ground fault protection, as well as impact offset of the protection. The following shows the fragment of urban power distribution network to better illustrate.

Vertical and horizontal grounds, which together form a grounding device, are used in the performance of grounds.

Grounding device is used for:

- Safety protection of operating personnel (protection ground);

- Connection of electric installation neutral (system ground);

- Connection of lightning protectors.

One and the same grounding device performs all of listed function, that's why the choosing of a grounding device is determined by ruthless requirements and in result of the calculation are accepted by wide safety margins. At the substations on the schema for which will be made a calculation the grounding is the protection ground consisting of a general grounding installed on the one of the substations.

At the electric installation with the insulated neutral the grounding device calculation should be made in the following succession:

1) Selection of grounding device schema: 
- Determining the required resistance of grounding device $-R_{G D}$.

- Determining the design resistance of soil $\rho$;

- Determining the required resistance of vertical electrode;

2) Grounding device configuration refinement:

- Determining the stub effervescive- $\eta_{B}, \eta_{r}$;

- Casting-off the number of vertical electrode- $n$;

- Determining the resistance of connection strap;

- Determining the common ground grid;

- Tolerable value design of step and touch potentials.

Electrode arrangement is shown in Figure 3 is assumed as grounding device schema.

It is taken to create the grounding device in the form of vertical rods with the 5 $\mathrm{m}$ length and $12 \mathrm{~mm}$ cross section $-l_{\text {rod }}=5 \mathrm{~m}, d=12 \mathrm{~mm}$. The distance between the vertical members is $5 \mathrm{~m}-a=5 \mathrm{~m}$, the primary number of rods is 12 . Vertical rods are connected by horizontal bar, the area when connecting the elements is $b$ $=40 \times 4 \mathrm{~mm}^{2}$, the overall bar length according to plan is $-l_{\text {cond }}=60 \mathrm{~m}$.

The required resistance of grounding device is used together to electric installations with voltage below and up to $1000 \mathrm{~V}$ with the insulated neutral should be not more $4 \mathrm{Om}, R_{G D}=4 \mathrm{Ohm}$ [5].

The soil resistivity is determined by the formula [1]:

$$
\rho_{\text {calc }}=k_{\text {seas }} \rho
$$

where $\rho$ is the soil resistivity measured by normal amount of moisture, $k_{\text {seas }}$ is the seasonality fluctuation coefficient that takes the soil freezing and drying.

Soil at the substation for which is designed the grounding device is weakly-moist loamy sand. The ground resistivity is taken as $\rho=300 \mathrm{Ohm} / \mathrm{m}[6]$. Seasonality fluctuation coefficient for the Izone, which is the zone with the most frigid climate, is taken as:

$K_{\text {seasRod }}=1.9$ is the seasonality fluctuation coefficient for the vertical ground conductor;

$K_{\text {seasCond }}=5.8$ is the seasonality fluctuation coefficient for the horizontal ground conductor;

The laying depth of the vertical ground conductor is $f=0.7 \mathrm{~m} \mathrm{[6]}$.

The vertical ground conductor resistance is determined by the formula:

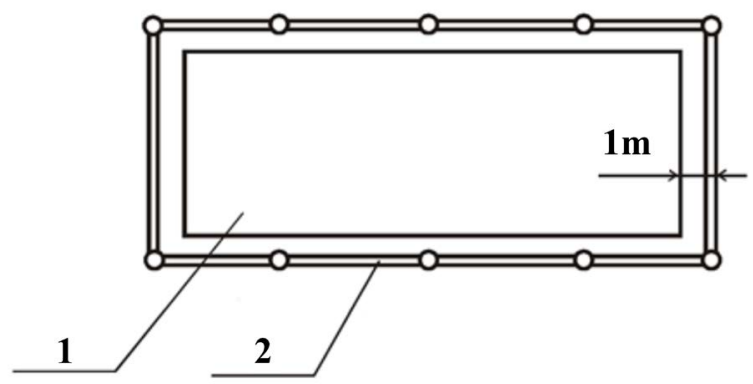

Figure 3. Grounding device plan: 1-the area occupied by installations; 2-the grounding loop. 


$$
r_{\text {rod }}=\frac{\rho_{\text {calc }}}{2 \pi l_{\text {rod }}}\left(\ln \frac{2 l_{\text {rod }}}{d}+\frac{1}{2} \ln \frac{2 t+\frac{l_{\text {rod }}}{2}}{2 t-\frac{l_{r o d}}{2}}\right)=\frac{300 \cdot 1.9}{2 \cdot \pi \cdot 5}\left(\ln \frac{2 \cdot 5}{12}+\frac{1}{2} \ln \frac{2 \cdot 1.75+\frac{5}{2}}{2 \cdot 1.75-\frac{5}{2}}\right)=9.937 \mathrm{Ohm}
$$

where $t$ is the depth from ground surface to mid-electrode,

$$
t=f+\frac{l_{B}}{2}=0.7+\frac{5}{2}=1.75 \mathrm{~m}
$$

The distance between the vertical ground conductor to the length thereof is equal to $a / l=1$, stub effervescive has the following values:

$\eta_{\text {rod }}=0.52$ - stub effervescive (the vertical ground conductor);

$\eta_{\text {cond }}=0.32$ - stub effervescive (the horizontal ground conductor);

The necessary number of vertical rods is determined by the formula [2]:

$$
n=\frac{r_{\text {rod }}}{R_{G S} \eta_{\text {rod }}}=\frac{9.937}{4 \cdot 0.52}=4.778 \approx 5
$$

According to the calculation the necessary number of vertical rods is 5 .

The ground-continuity conductor resistance is determined by the formula:

$$
r_{\text {cond }}=\frac{\rho_{\text {calc }}}{\pi l_{\text {cond }}} \ln \frac{1.5 l_{\text {cond }}}{\sqrt{b t}}=\frac{300 \cdot 5.8}{\pi \cdot 60} \ln \frac{1.5 \cdot 60}{\sqrt{40 \cdot 10^{-3} \cdot 0.7}}=6.288 \mathrm{Ohm}
$$

The ground-continuity conductor resistance in the grounding loop from 12 electrodes:

$$
R_{\text {cond }}=\frac{r_{\text {cond }}}{\eta_{\text {cond }}}=\frac{6.288}{0.32}=19.650 \mathrm{Ohm}
$$

The necessary resistance of vertical rods is:

$$
R_{\text {rod }}=\frac{R_{\text {rod }} R_{G S}}{R_{\text {cond }}-R_{G S}}=\frac{19.650 \cdot 4}{19.650-4}=5.02 \mathrm{Ohm}
$$

The exact number of vertical ground conductors:

$$
N_{\text {rod }}^{\prime}=\frac{r_{\text {rod }}}{R_{\text {rod }} \eta_{\text {rod }}}=\frac{9.937}{5.02 \cdot 0.52}=3.81 \approx 4
$$

Thus the number of vertical ground conductors is 4 .

The grounding device resistance will be determined as [2]:

$$
R_{G S}=\frac{R_{\text {cond }} \cdot R_{\text {rod }}}{R_{\text {cond }}+R_{\text {rod }}}=\frac{19.650 \cdot 3.6}{19.650+3.6}=3.38 \mathrm{Ohm}
$$

The calculated grounding device resistance is less than standard value it means that the ground network is effective.

In this section the casting-off the analytical calculation of the general grounding which is installed on the substation of the urban power distribution network was done. By choosing the preliminary size and number of electrodes the grounding device resistance was calculated, the result of calculation satisfies the requirements of the Rules of Electrical Facilities Maintenance. The given analytical method does not enable to make an exact calculation of step and touch potentials, that's why at this stage qualitative assessment of the grounding network 
can't be done. By using the result, we shell look to software-based calculation where it is possible to get the tolerable safe values of step and touch potentials.

\section{Software-Based Calculation of a Grounding Device}

The software-based calculation is based on two calculation methods: IEEE and FEM methods. Theselectionofthisorthatmethoddependsoninstanceanditisgenerallydetermined be design convenience. Main advantage of FEM is the possibility to create different forms of grounding devices, while IEEE method suggests only standard forms, as this method is based on subdivision of the field pattern on the elementary units (boxes) and therefore in order to reduce complex shape elementary units it is necessary to scale up massively the number of units [7]. Within a FEM elementary unit is the etriangle. The triangle can be different geometry for example where the field uniformly distributes the approximation is carried out by bigtriangles, small triangle will be used where the fieldintensivevariesanditisrequiredtoensureexactaccuracyoftracing. In the last case system order of equations is lower, computation time decreases [8]. Taking into account the features software-based calculation of grounding device will be based on the FEM. Such calculation of the grounding device resistance based on the calculation of currents and potentials at different points, that are bounded this grounding device. Further the grounding device resistance is calculated according to the Ohm's law [9].

It is necessary to design an urban power network for the calculation in the software package. The fragment of power distribution network is illustrated in Figure 4.

The software-based calculation starts from the setting of the parameters in the window of the horizontal and vertical conductors, Figure 5, Figure 6.

The following parameters are set in the window of the horizontal conductor editor:

- Length - the length of the conductor/rod in $\mathrm{m}$ If the length is altered, $\mathrm{X} 2, \mathrm{Y} 2$, and $\mathrm{Z} 2$ are changed accordingly. If $\mathrm{X} 1, \mathrm{Y} 1, \mathrm{Z} 1, \mathrm{X} 2, \mathrm{Y} 2$, and $\mathrm{Z} 2$ values are entered, the length is changed accordingly;

- $\mathrm{X} 1$-the $\mathrm{X}$ coordinate of one end of the conductor/rod in meters;

- $\mathrm{Y} 1$ - the $\mathrm{Y}$ coordinate of one end of the conductor/rod in meters;

- $\mathrm{Z} 1$ - the $\mathrm{Z}$ coordinate of one end of the conductor/rod in meters, referenced from the top edge of the top layer;

- X2-the X coordinate of the other end of the conductor/rod in meters;

- Y2-the Y coordinate of the other end of the conductor/rod in meters;

- $\mathrm{Z} 2$ - the $\mathrm{Z}$ coordinate of one end of the conductor/rod in meters, referenced from the top edge of the top layer;

- Diameter-the Rod diameter in cm or inches, used only in the Rod editor;

- Type-the type of conductor/rod material;

- Size-the conductor cross-sectional area in $\mathrm{mm} 2$, used only in the Conductor editor; 


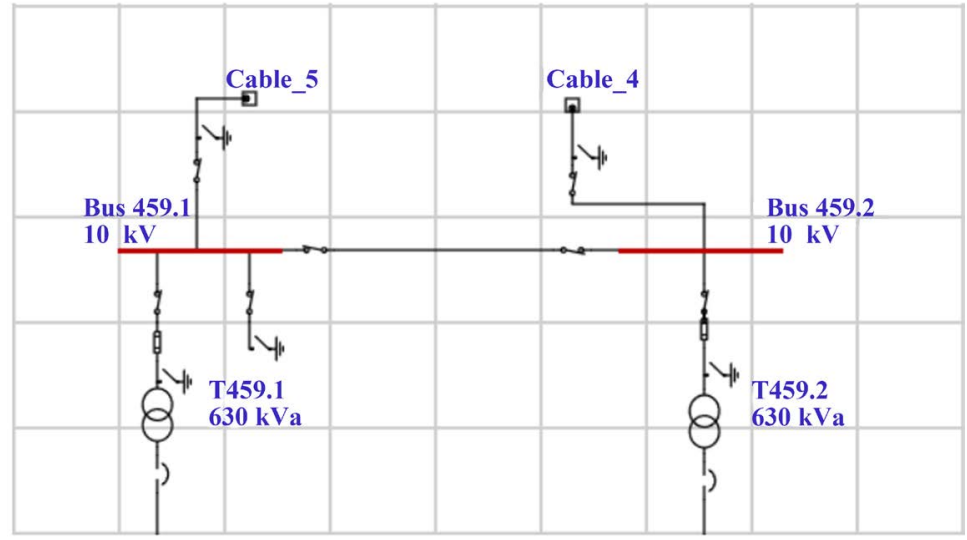

Figure 4. The fragment of the research substation.

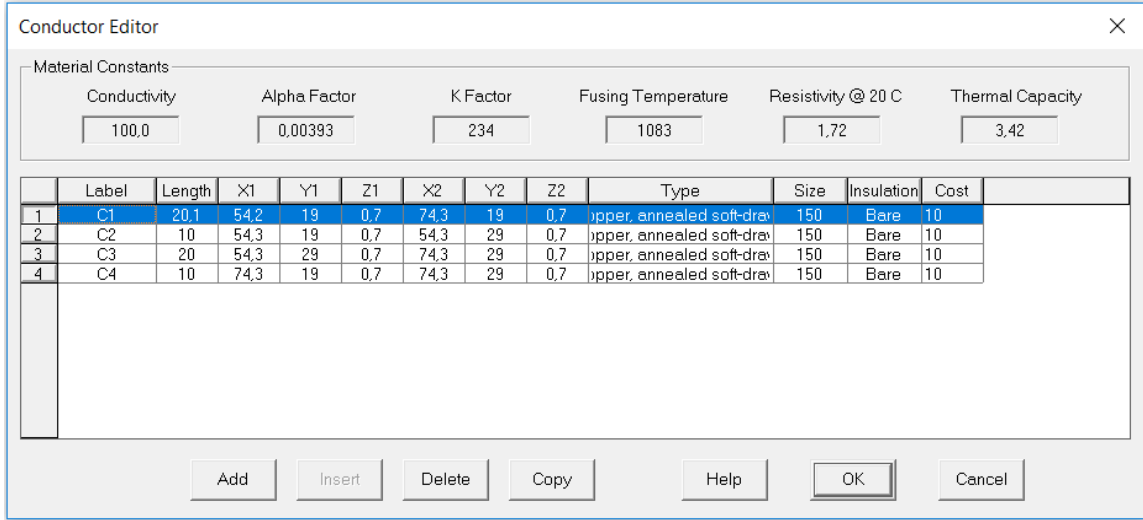

Figure 5. The conductor editor.

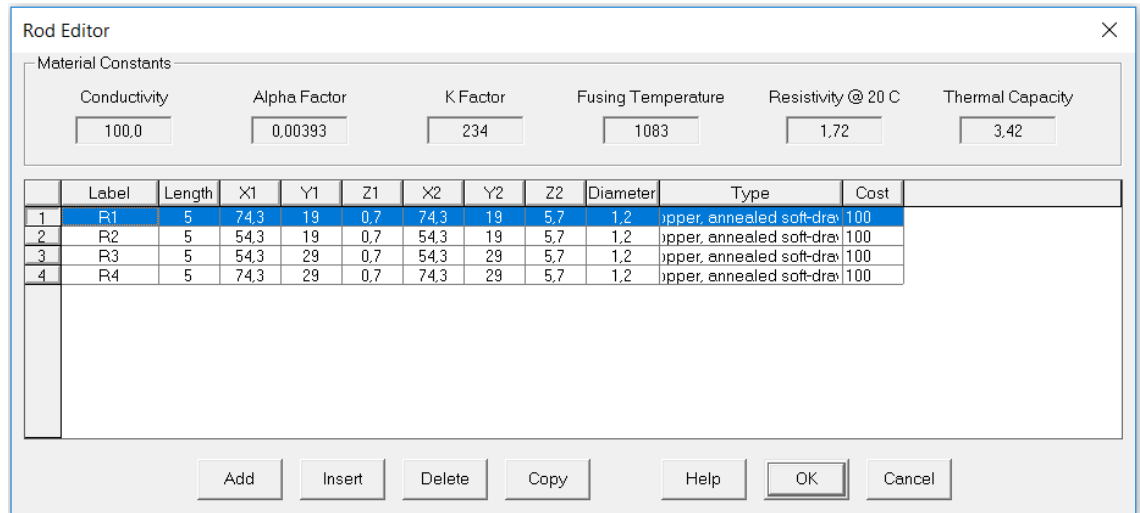

Figure 6. The rod editor.

- Insulation-the conductor insulation type, used only in the Conductor editor;

- Cost - the cost in $\$ / \mathrm{m}$ for a conductor, cost in $\$ / \operatorname{rod}$ for a rod.

- The soil parameters are entered after the grounding device customization, Figure 7.

Further the software-based calculation is implemented, the results are shown on Figure 8. 


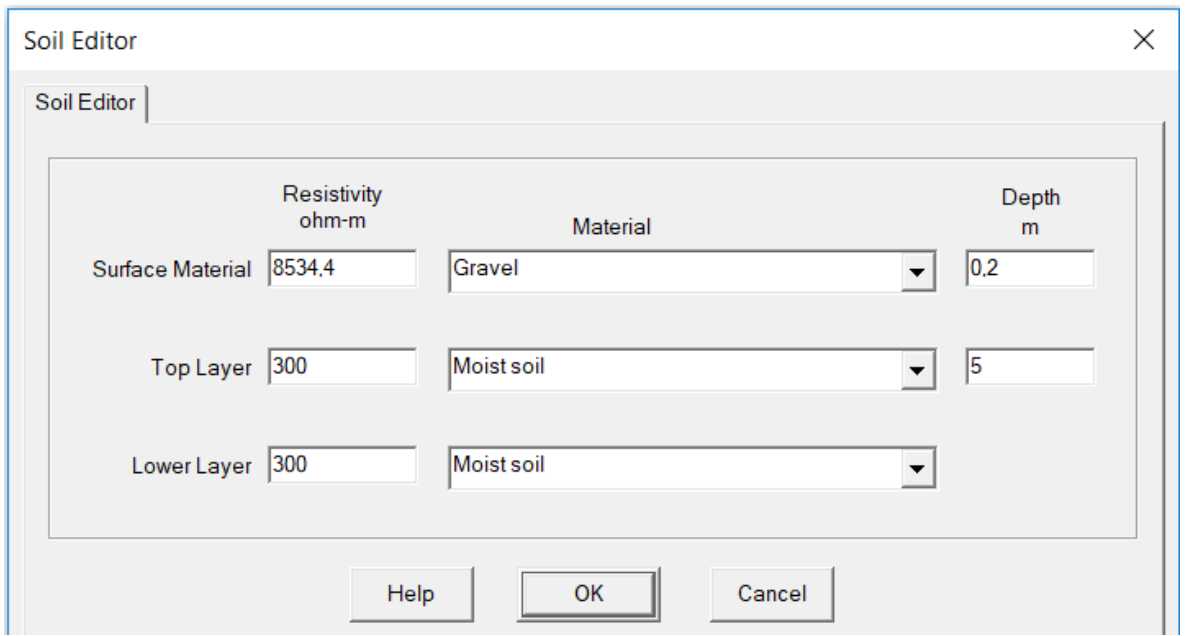

Figure 7. Soil editor.

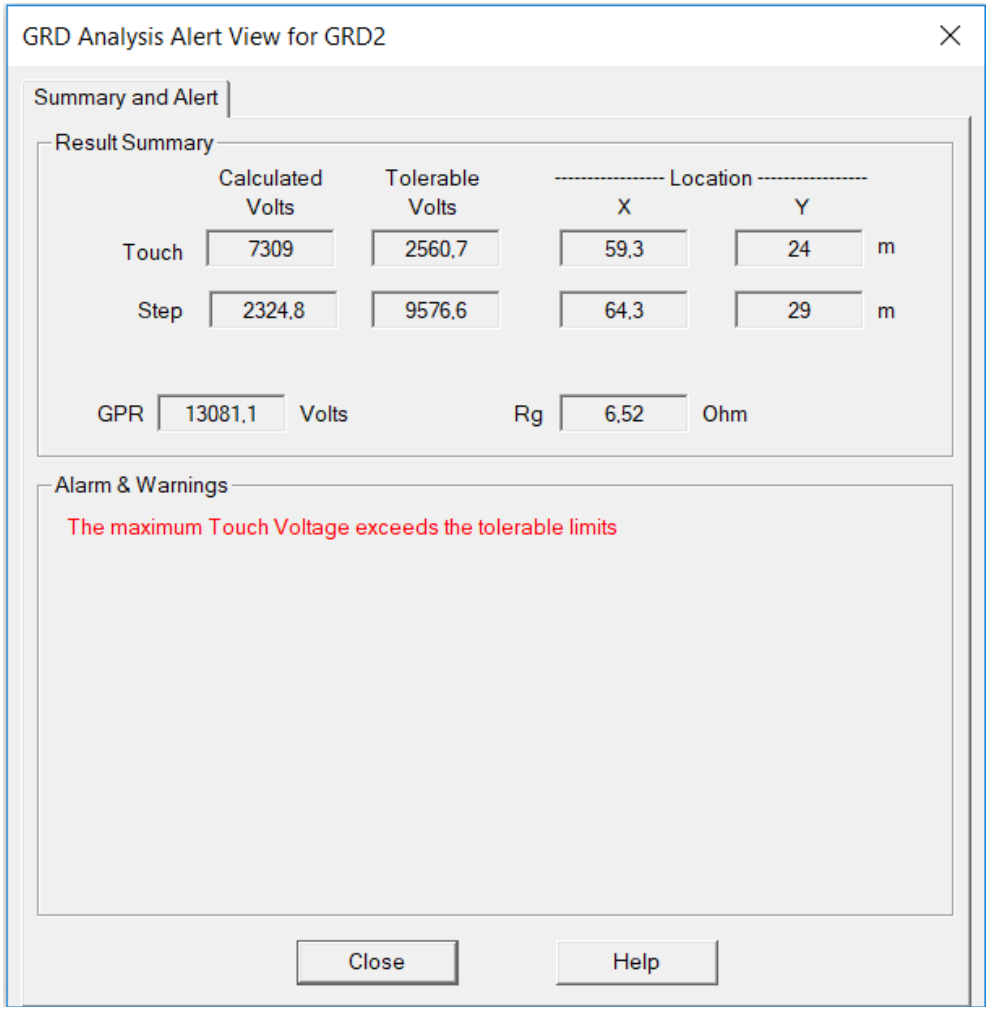

Figure 8. The results of grounding device calculation.

According to the calculation results, the grounding device resistance is above set value $4 \mathrm{Ohm}$, as the touch potential is above tolerable limit in $2560.7 \mathrm{~V}$. The tolerable limit is calculated by the programme on the base of the created model of the urban power distribution network [10].

AS the result can be included in tolerable limit of the touch potential, then it is necessary to change the grounding device configuration. Toresolveth is problem 4 rods and 4 conductors are added. In the research the objective is to create grounding construction with the tolerable electrical parameters with a minimum 
of cost. The grounding device construction then assumes the following form, Figure 9.

\section{The Calculation Results}

The results of grounding device calculation with the revised design are given below, Figure 10.

Simulation of the grounding device with the help of FEM allows to get graphs of voltage, touch and step potentials. The potential distribution over the surface bounded the grounded device is shown color. The graphs are shown on Figures 11-13.

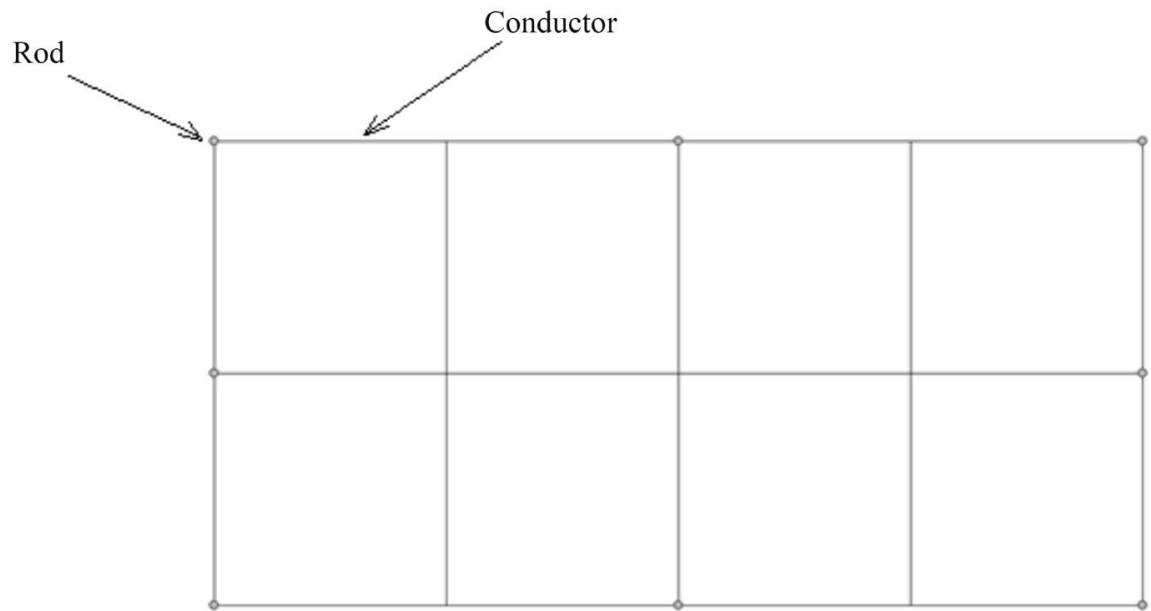

Figure 9. The grounding device construction.

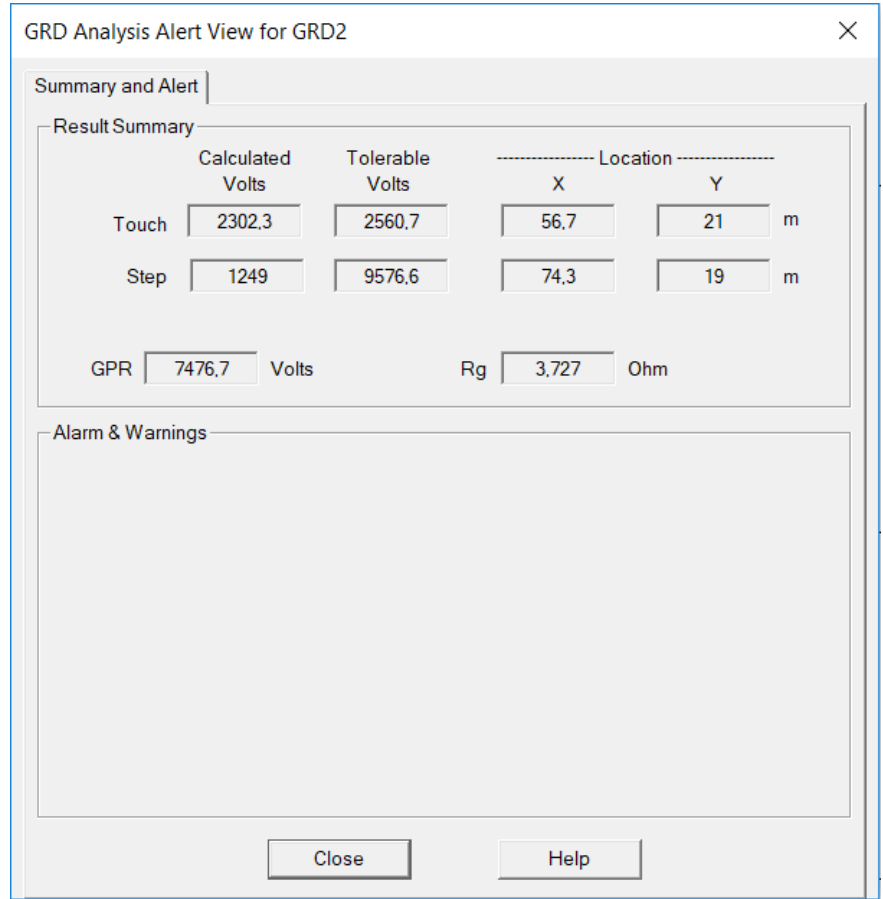

Figure 10. The results of software-based calculation. 


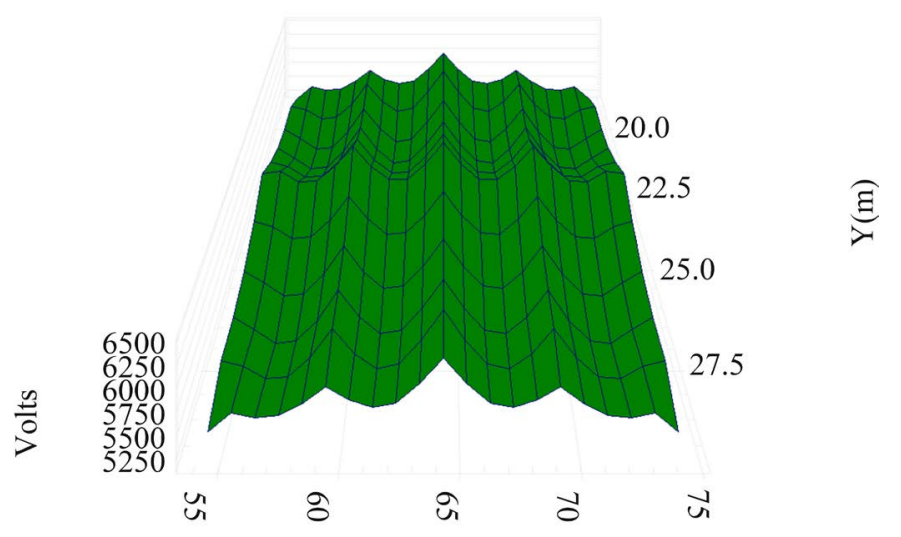

Figure 11. The voltage distribution.

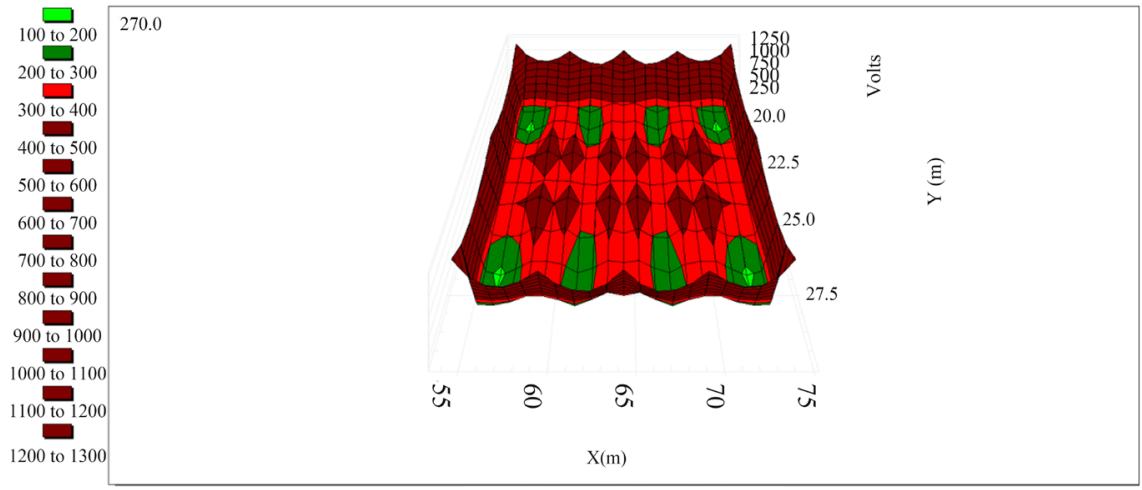

Figure 12. The step potential distribution.

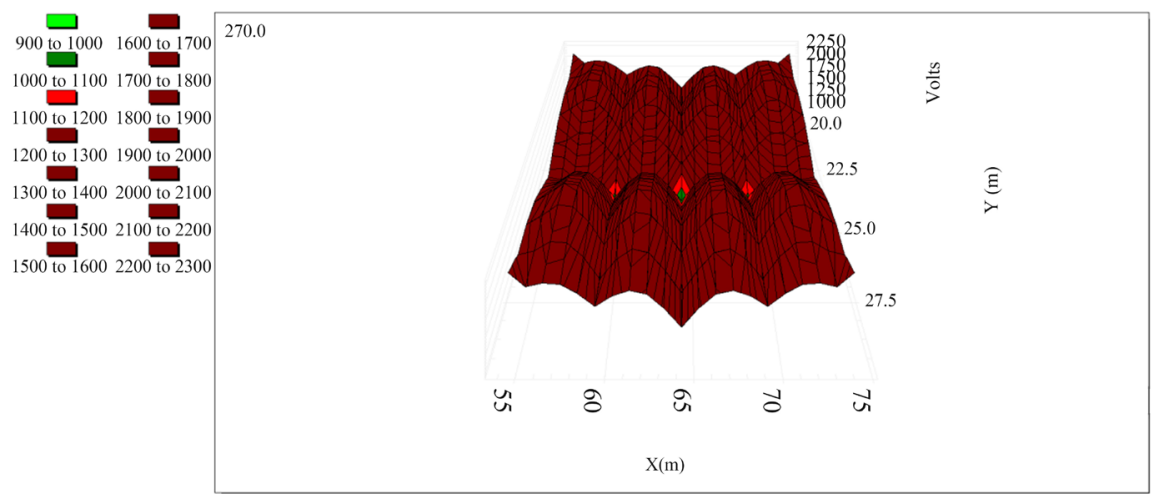

Figure 13. The touch potential distribution.

As shown on the figures, voltage grows to reach the maximum value in the points the most distant from the conductors. The greatest decline in voltage can beget by increasing the number of rods and horizontal bars or by increasing the rod cross section and choosing the conductors with higher conductivity [11]. A significant role also is played by soil conductivity the increasing of which can be done by filling pits for rod by salt. It is quite difficult procedure, which is required a big number of measurements, within the framework it can't be done [12]. 
Economic costs of the ground network is presented in Table 3, Table 4. The cost of $1 \mathrm{~m}$ material of horizontal and vertical conductors was set up as calculation basis [13].

As a result of the changes to the grounding device configuration the total cost is $1900 \$$, Table 5 .

\section{Conclusion}

In the paper, the calculation of the grounding device which is installed on the substation $10 / 0.4 \mathrm{kV}$ of the urban power distribution network was done. Analytical and software-based methods are used as calculation basis. Analytical method does not enable to make an exact calculation of all parameters of a grounding device; it is used for qualitative assessment of the parameters involved in the calculation [14]. Analytical calculation is just a basis for a software-based calculation,

Table 3. Conductor data.

\begin{tabular}{|c|c|c|c|c|c|}
\hline Label & type & Cross Section, $\mathrm{mm}^{2}$ & Length, $\mathrm{m}$ & Insulated Yes/No & Cost, $\$ / \mathrm{m}$ \\
\hline $\mathrm{C} 1$ & & 150 & 20 & No & 10 \\
\hline $\mathrm{C} 2$ & & 150 & 10 & No & 10 \\
\hline $\mathrm{C} 3$ & & 150 & 20 & No & 10 \\
\hline $\mathrm{C} 4$ & Copper, annealed & 150 & 10 & No & 10 \\
\hline $\mathrm{C} 5$ & soft-drawn & 150 & 10 & No & 10 \\
\hline C6 & & 150 & 10 & No & 10 \\
\hline $\mathrm{C} 7$ & & 150 & 20 & No & 10 \\
\hline C8 & & 150 & 10 & No & 10 \\
\hline
\end{tabular}

Table 4. Rod data.

\begin{tabular}{|c|c|c|c|c|c|}
\hline Label & type & Diameter, cm & Length, m & Insulated Yes/No & Cost, \$/Rod \\
\hline $\mathrm{R} 1$ & & 1.2 & 5 & No & 100 \\
\hline $\mathrm{R} 2$ & & 1.2 & 5 & No & 100 \\
\hline R3 & & 1.2 & 5 & No & 100 \\
\hline R4 & Copper, annealed & 1.2 & 5 & No & 100 \\
\hline R5 & soft-drawn & 1.2 & 5 & No & 100 \\
\hline R6 & & 1.2 & 5 & No & 100 \\
\hline R7 & & 1.2 & 5 & No & 100 \\
\hline $\mathrm{R} 8$ & & 1.2 & 5 & No & 100 \\
\hline
\end{tabular}

Table 5. Total cost.

\begin{tabular}{|c|c|c|c|c|c|c|}
\hline & Conductor & & Rod & & & \\
\hline Total, $\mathrm{N}^{\circ}$ & Total length, $\mathrm{m}$ & Cost, \$ & Total, $\mathrm{N}^{\circ}$ & Total length, $\mathrm{m}$ & Cost, \$ & \\
\hline 8 & 110 & 1100 & 8 & 40 & 800 & 1900 \\
\hline
\end{tabular}


which allows to get the step and touch voltage graphs and moreover to make an optimization. In the optimization result, the values of all parameters are tolerable parameters, indicated in the Rules of Electrical Facilities Maintenance [2]. As a result of the economic costs, the total grounding device cost is $1900 \$$.

\section{Conflicts of Interest}

The authors declare no conflicts of interest regarding the publication of this paper.

\section{References}

[1] Muatasim, R. (2013) Earthing Design Using Finite Element Method. University of Khartoum, 45.

http://khartoumspace.uofk.edu/bitstream/handle/123456789/91/EARTHING\%20D ESIGN\%20USING\%20FINITE\%20ELEMENT\%20METHOD?sequence=1\&isAllow $\underline{\text { ed }=\mathrm{y}}$

[2] Kabyshev, A.V. (2006) Lightning Protection of Electrical Installation Systems. TPU Tomsk, 77, 124.

http://portal.tpu.ru/departments/kafedra/espp/literatura/Tab/M_Molniazazh_Kabis hev.pdf

[3] Federal Agency on Technical Regulation and Metrology (2017) Rules of Electrical Facilities Maintenance. PUE 7 Izdaniye, 1, 8.

[4] Petukhov, S.V., Butakov, S.V. and Radyushin, V.V. (2011) Calculation of the Grounding Device. MSU, Arkhangelsk, 7, 21.

https://narfu.ru/university/library/books/0616.pdf

[5] Hatim, G. (2012) Calculation of Grounding Resistance and Earth Surface Potential for Two Layer Model Soil. International Journal of Electrical Engineering \& Technology (IJEET), 158, 156-163.

https://docslide.us/documents/calculation-of-grounding-resistance-and-earth.html

[6] Dashkovsky, A. (2008) Calculation of the Grounding Device. TPU, Tomsk, 2, 10.

[7] Uma, U., Uzoechi, L. and Robert, B. (2016) Optimization Design of Ground Grid Mesh of 132/33 kv Substation Using ETAP. Nigerian Journal of Technology (NIJOTECH). 926, 926-934.

https://www.ajol.info/index.php/njt/article/viewFile/145131/134728 https://doi.org/10.4314/njt.v35i4.30

[8] Abouzeid, O. and Syakur, A. (2018) Design of Grounding System at $150 \mathrm{kV} \mathrm{Kra-}$ pyak Substation by Grounding System Software. IJESC, 17180, 17178-17185.

http://www.ijesc.org/upload/319ae0f5b02d2484c3451e4ac41597f2.Design\%20of\%20Grou nding\%20System\%20at\%20150\%20kV\%20Krapyak\%20Substation\%20by\%20Grounding \%20System\%20Software.pdf

[9] (2000) IEEE Guide for Safety in ac Substation Grounding, ANSI/IEEE Std. 80. IEEE Society, New York.

[10] Muhammad, U.C., MBilal, C., Adnan, B. and Aslam, M. (2015) A Comparison of Ground Grid Mesh Design and Optimization for 500kv Substation Using IEEE 80 and Finite Element Methods. Electrical and Electronics Engineering. An International Journal (ELELI), 4, 131-145.

[11] Raju, S. and Pardharadhi, G. (2012) Optimal Design Planning of Ground Grid for Outdoor Substations in MEA's Power Distribution Substation. Journal of Engi- 
neering Research and Applications.

[12] Guemes, J.A., Hernando, F.E., Rodrigez, F. and Ruiz, J.M. (2006) A Practical Approach of Determining the Grounding Grids. IEEE Transactions on Power Delivery, 21.

[13] Heidler, F. and Zischank, W. (2008) Parameters of Lightning Current Given in IEC 62305-Background, Experience and Outlook. 29th International Conference on Lightning Protection. http://www.iclp-centre.org/pdf/Invited-Lecture-3.pdf

[14] (2014) DEHN + SÖHNE: Lightning Protection Guide. 3rd Updated Edition, DEHN + SÖHNE GmbH. 